\title{
Cloning, nucleotide sequence and characterization of a gene encoding superoxide dismutase from Campylobacter jejuni and Campylobacter coli
}

\author{
Desmond Purdy and Simon F. Park \\ Author for correspondence: Simon F. Park. Tel: +44 734 357227. Fax: + 44734267291.
}

Institute of Food Research, Reading Laboratory, Earley Gate, Whiteknights Road, Reading RG6 2EF, UK

\begin{abstract}
Genes encoding superoxide dismutase (SOD : EC 1.15.1.1) were cloned from Campylobacter jejuni NCTC 11351 and Campylobacter coli UA585 by heterologous complementation of a SOD-deficient Escherichia coli mutant. Deletion analysis of the cloned $C$. jejuni DNA assigned the sod gene to a $1.2 \mathrm{~kb}$ insert and this contained an open reading frame of $660 \mathrm{bp}$. The deduced gene product of 220 amino acids was $71 \%$ identical to the $E$. coli iron-containing SOD and $60 \%$ identical to the $E$. coli manganese-containing SOD. The recombinant SOD was expressed at high levels in $E$. coli and protected a sodA sodB double mutant from the toxic effects of methyl viologen. Nucleotide sequence analysis of the corresponding gene from C. coli showed it to be $92 \%$ identical to that from $C$. jejuni.
\end{abstract}

Keywords: Campylobacter jejuni, Campylobacter coli, superoxide dismutase, cloning

\section{INTRODUCTION}

Species of the genus Campylobacter are some of the most prevalent pathogens causing acute gastroenteritis in man (ACMSF, 1993; Walker et al., 1986). Campylobacters have limited aerotolerance and are widely recognized as being microaerophilic (Hoffman, 1979a, b). A recent study (Jones et al., 1993), however, has suggested the possibility that these organisms are capable of surviving for extended periods in the environment after adaptation to an aerobic metabolism. Prolonged survival of any organism in air necessarily entails mechanisms to eliminate the deleterious effects produced by exposure to superoxide radicals. In this respect, superoxide dismutase (SOD: EC 1.15.1.1), which is found in almost all organisms exposed to oxygen (Fridovich, 1986), catalyses the dismutation of superoxide radicals and is thought to form part of the defence mechanism which protects cells from oxygen toxicity (Fridovich, 1978). Accordingly, mutants of Escherichia coli which are deficient in SOD activity are hypersensitive to conditions of oxidative stress and consequently cannot grow aerobically when cultivated in minimal media (Carlioz \& Touati, 1986). Because of its role in cellular defence against oxidative stress, SOD is

Abbreviation: SOD, superoxide dismutase.

The GenBank accession numbers for the sequences reported in this paper are $X 76692$ (Campylobacter jejuni) and X76693 (C. coli). also considered to contribute to the pathogenicity of certain intracellular bacterial pathogens since macrophages can kill ingested bacteria by oxidative mechanisms (Haas \& Goebel, 1992). Accordingly, mutants of Sbigella flexneri which are deficient in a manganese-containing SOD show decreased survival in macrophages (Franzon et al., 1990).

Studies with other bacterial species have highlighted the important role SOD plays in the physiology and pathogenicity of bacterial pathogens (Haas \& Goebel, 1992). To date, however, no attempts have been made to characterize the genes encoding SOD in any Campylobacter spp. or indeed any other microaerophilic bacterium. Previously, SOD activity has been detected in 23 strains of Campylobacter spp. (Kikuchi \& Suzuki, 1984) and it has been suggested that $C$.jejuni may possess an iron-requiring SOD (Hoffman et al., 1979a). To assess the contribution of SOD to the survival of campylobacters in air and during infection we have cloned the genes encoding SOD from Campylobacter jejuni and C. coli, the most frequently isolated campylobacters associated with diarrhoeal disease (Griffiths \& Park, 1990). We describe the nucleotide sequence of the genes and their expression in E. coli as enzymically active recombinant proteins.

\section{METHODS}

Bacterial strains and plasmids. C. jejuni NCTC 11351 (Type strain) was purchased from the National Collection of Type 
Cultures (Colindale) and C. coli UA585 was a generous gift from D. Taylor (University of Alberta, Edmonton). Eschericbia coli QC1799, ( $\mathrm{F}^{-} \Delta$ lac4169 rpsL $\Delta \operatorname{sod} A 3 \Delta \operatorname{sodB} 2 \mathrm{Km}^{\mathrm{r}}$ ) a $\operatorname{sod} A \operatorname{sod} B$ double mutant incapable of growth on minimal medium containing methyl viologen, was kindly supplied by D. Touati (Institute Jaques Monod, Paris). The plasmid pTZ19R (Mead et al., 1986), used as a general cloning vector, was supplied by Pharmacia. Campylobacters were grown at $37^{\circ} \mathrm{C}$ on Mueller-Hinton ( $\mathrm{MH}$ ) agar, under microaerophilic conditions using the recommended gas generating kit (Oxoid). E. coli QC1799 was routinely cultured on LB agar plates (Maniatis et al., 1982). When necessary, ampicillin was included in growth media at $100 \mu \mathrm{g} \mathrm{ml}^{-1}$ to maintain plasmid selection.

Cloning and DNA analysis. Genomic DNA was isolated from campylobacters using guanidium thiocyanate (Pitcher et al., 1989). Plasmid libraries of chromosomal DNA from C. jejuni and $C$. coli were established in dephosphorylated pTZ19R using genomic DNA partially digested with HindIII, as described by Maniatis et al. (1982). Following ligation, libraries were used to transform E. coli QC1799 by electroporation as described by Dower et al. (1988). After transformation, cells were washed three times in sterile $\frac{1}{4}$ strength Ringers solution before plating. Transformants were selected by aerobic growth on M9 minimal agar (Maniatis et al., 1982) containing methyl viologen $(0.05 \mu \mathrm{M})$ and ampicillin $\left(100 \mu \mathrm{g} \mathrm{ml}^{-1}\right)$ as described by Carlioz \& Touati (1986).

Plasmid deletion was carried out using an exonuclease III/mung bean nuclease kit following digestion of pJSOD1 with KpnI and XbaI (Northumbria Biologicals). A series of nested plasmid deletions, prepared in this manner, was then used to transform E. coli QC1799 to determine the smallest size of DNA insert which conveyed resistance to methyl viologen using the selection procedure described above.

Nucleotide sequence analysis was carried out by the dideoxy chain termination method (Sanger et al., 1977), using a Sequenase version 2.0 kit (USB). Initially, nucleotide sequence was determined from both DNA strands using the M13 universal forward and reverse primer sites and the deletion plasmid pDEL1 as template. Further oligonucleotide primers of approximately 20 nucleotides were designed according to the sequence information and synthesized using a 391 DNA synthesizer (Applied Biosystems). The sequence of the $C$. coli sod gene was determined using these same primers. Computer analysis of the sequence data was carried out using the Wisconsin molecular biology software package (Devereux et al., 1984).

DNA/DNA hybridizations. DNA/DNA hybridizations were carried out using a non-radioactive ECL gene detection kit (Amersham). Chromosomal DNA was restricted using either HindIII or PstI and electrophoresed on a $0.8 \%$ agarose gel. After depurination of the DNA, using $250 \mathrm{mM} \mathrm{HCl}$, DNA was transferred to $\mathrm{Hybond} \mathrm{N}+$ nitrocellulose membranes (Amersham) using an alkali transfer procedure (Maniatis $e t$ al., 1982). A DNA probe, generated using a $666 \mathrm{bp} \mathrm{HindIII}$ fragment from pDEL1, was then used to detect homology.

Protein extraction and analysis. Crude cell lysates of E. coli in L-broth or C. jejuni grown microaerophilically on $\mathrm{MH}$ agar were prepared from overnight cultures. Harvested cells were washed twice in $0.15 \mathrm{M}$ Tris $/ \mathrm{HCl}, \mathrm{pH} 7 \cdot 0$, and resuspended in $0.15 \mathrm{M}$ Tris $/ \mathrm{HCl}, \mathrm{pH} 7 \cdot 0$, containing $0.2 \mathrm{mg}$ lysozyme $\mathrm{ml}^{-1}$ and $0 \cdot 1 \mathrm{mM}$ EDTA. Five cycles of freeze thawing, using a com- bination of liquid $\mathrm{N}_{2}$ and $42{ }^{\circ} \mathrm{C}$, were used to lyse the cells. The lysates were then cleared by centrifugation at $20000 \mathrm{~g}$ for $20 \mathrm{~min}$. Soluble cellular proteins were extracted in the supernatant.

Cell lysates were electrophoresed under both denaturing and non-denaturing conditions (Laemmli, 1970). Under nondenaturing conditions samples were not boiled and SDS and $\beta$-mercaptoethanol were omitted from all buffers. Gels were stained for SOD activity using the method described by Beauchamp \& Fridovich (1971).

\section{RESULTS}

\section{Cloning of the sod gene from C. jejuni NCTC 11351}

The E. coli strain QC1799 is a $\operatorname{sod} A \operatorname{sodB}$ double mutant and is, consequently, unable to grow aerobically when cultivated on minimal medium supplemented with methyl viologen (Carlioz \& Touati, 1986). A genomic library of DNA from C. jejuni NCTC 11351, which consisted of approximately 10000 independent clones with inserts of approximately $6.0 \mathrm{~kb}$, was constructed in E. coli QC1799. One transformant capable of growth on minimal media containing methyl viologen was isolated. This clone was found to harbour a plasmid, which contained an insert of approximately $4.5 \mathrm{~kb}$, and was designated pJSOD1.

\section{Localization of the sod gene in pJSOD1}

To locate the gene encoding the SOD activity, and to simplify the ensuing nucleotide sequence determination, unidirectional deletions were generated in p JSOD1 using exonuclease III and mung bean nuclease. The deletion derivatives generated were then used to transform $E$. coli QC1799 and selection made for the ability to complement the SOD-deficient phenotype of this strain. The smallest plasmid capable of conferring resistance to the toxic effects of methyl viologen retained a $1 \cdot 2 \mathrm{~kb}$ insert of $C$. jejuni DNA (data not shown). This plasmid, designated pDEL1, was used as template for nucleotide sequence determination.

\section{Nucleotide sequence of the sod gene from C. jejuni}

Nucleotide sequence analysis of the DNA insert in pDEL1 revealed an open reading frame of $660 \mathrm{bp}$ which could encode a potential polypeptide of 220 amino acids (Fig. 1) with a calculated molecular mass of $24804 \mathrm{Da}$. This corresponds well with the molecular mass of a protein of approximately $23.5 \mathrm{kDa}$ which was detected by denaturing SDS-PAGE in extracts of cells containing pDEL1 and pJSOD1 (see later). The nucleotide sequence of the putative C. jejuni sod gene shows $57 \%$ identity to the $E$. coli iron-containing SOD and $45 \%$ identity to the manganese-containing SOD. A putative ribosome binding site exists $11 \mathrm{bp}$ upstream of the ATG start codon (Gold, 1988). Putative -10 and -35 sites may also exist $49 \mathrm{bp}$ and $71 \mathrm{bp}$ upstream of the ATG start codon, respectively. These show homology to the consensus sequences predicted by Hawley \& McClure (1983). The $\mathrm{G}+\mathrm{C}$ content of the coding sequence is $32.6 \%$, which is 


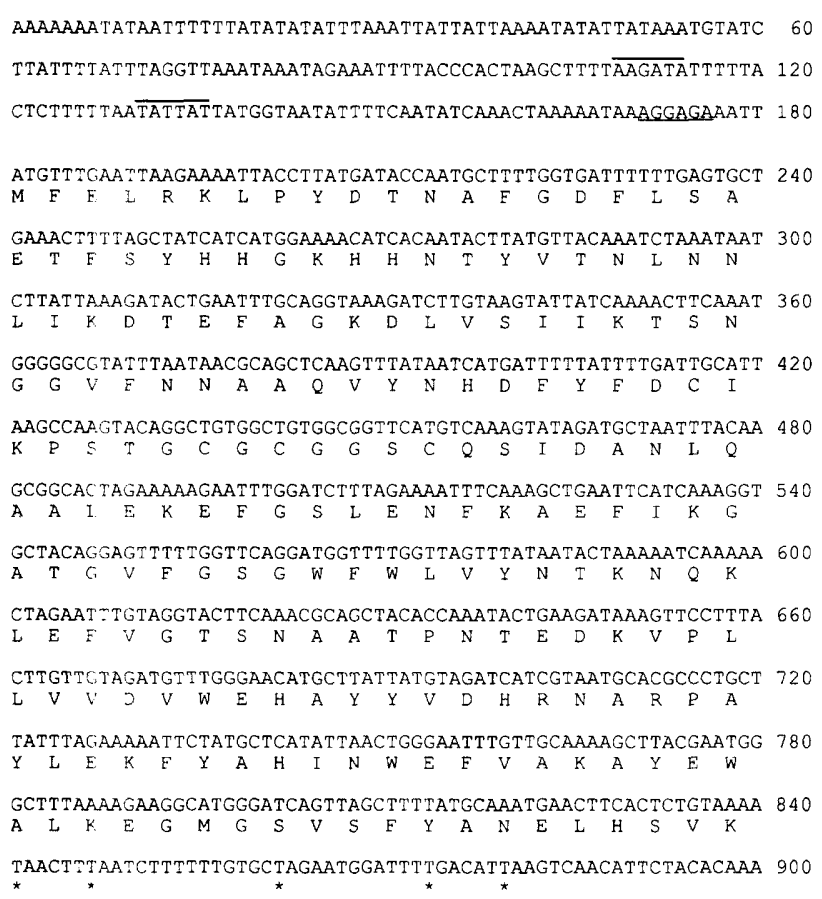

Fig. 1. Nucleotide sequence and amino acid translation of the sod gene of $C$. jejuni NCTC 11351 . The nucleotide sequence of a $900 \mathrm{bp}$ region of the $1.2 \mathrm{~kb}$ insert in pDEL1 is shown. A potential RBS is underlined. Promoter sequences homologous to the -10 and -35 regions of $E$. coli are denoted by horizontal lines above the sequence. Stop codons are shown by asterisks.

consistent with the low $\mathrm{G}+\mathrm{C}$ content of all Campylobacter species (Belland \& Trust, 1982).

Comparison of the putative amino acid sequence of the C. jejuni sod gene product with previously characterized sequences revealed $71 \%$ and $60 \%$ identity with the E. coli iron-dependent SOD and manganese-dependent SOD (Fig. 2) respectively. Furthermore, comparison of the putative amino acid sequence with the iron and manganese classes of SOD, as described by Parker \& Blake (1988), points to the cloned SOD having iron as its metal cofactor. The amino acid sequences of the cloned SOD gene matches the expected amino acid residue at four of the five primary determinants and 13 of the 17 secondary determinant residues predicted for iron containing SODs (Table 1).

\section{Sequence analysis of the $C$. coli sod gene}

To compare the gene encoding SOD from $C$. jejuni with that from another species of Campylobacter, the sod gene from $C$. coli UA585 was cloned in an analogous manner (data not shown). Nucleotide sequence analysis revealed a $660 \mathrm{bp}$ open reading frame which could encode a polypeptide 220 amino acids long (Fig. 2). The nucleotide sequence of the open reading frame showed $92 \%$ identity
Human (Mn) E.coli (Mn) E.coli ( $\mathrm{Mn})$ E.coli $(\mathrm{Fe}$ C. jejuni

Human (Mn) E.coli (Mn) E.coli (Fe) C. jejuni c. coli

Human (Mn) E.coli (Mn) E.coli (Fe) C. jejuni

C.jejuni

Human (Mn)

E. coli (Mn

. coli ( $\mathrm{Ee}$

C. jejun

C.coli

Human (Mn)

E. coli (Mn)

E. $\operatorname{coli}(\mathrm{Fe})$

C. jejuni

C.coli

c. jejuni c. coli
KHSLPDLPYD YGALEPH INAQ IMQ LHHSKHHAAYVNNLNVTEEKY SYTLP SLPYA YDALEP HFDKQTME I HH TKHHQTYVNNANAALESL SEMTY - ELRKLPYDTNAFGDFLSAETF SYHKGKAHNTYVINLNNLIKDT QEALAKGDVTAQI--- ---ALQP ALKFNGGGH INHS I FWTNLSP-AFEGKSLEEI I-R------SSEGGVFNNAAQVWNHTF YWNCLAP-EFAGKDIVSI I-K------TSNGGVE NNAAQVYNHDF YFDCIKP-EFASKDLVSI I-K------SSSGGVF NNAAQVYNHDF YFDC I KP-

----NGGGE-P-K-GELLEAIKRDFGSEDKFKEKITAASVGVQSSG - - GTTL-Q---GDLKAAIERDFGSVDENRAEFEKAAASRFGSG ---NAGGE-P-T-GKVAEAI AASFGSFADFKAOFTDAAI KNFGSG STGCGCGGSCOSIDANLOAALEKEFGSLENFKAEF IKGATGVEGSG I TGCGCGGSCOSMD ANLQAALEKEFGSLENFRAEF IKGATGVFGSG

WGWLGFN-KERGHLQIAACPNOD-PLOGTT----GL I PLLG IDVWE WAWLVLK---GDKLAAVSTANDOSPLMGEAISGASGEPIIWLGVWE WAWLVLK---GDKLAAVSTANDQSP LMGEA I SGASGEP I LWLGVWE
WTWLVKN-S-DGKLAIVSTSNAGTPLTTDA-----TP L TVDFWE WTWLVKN-S-DGKLAIVSTSNAGTPLTTDA-----TP LLTVDFWE
WFWLVYNTKNQ-KLEFVGT SNAATPNTED----KVPLIVVDVWE WFWLVYNTKNQ-KLEFVGTSNAATR ITED-----KVPLIVVDVWE

HAYYLQYKNVRPDY LKAI WNVINWENVTERY - MACK-K HAYYLKFONRPPDYIKEFWNVVNWDE AAARF - AAAK-K HAYYIDYRNARPGYLEHEWAIVMUEFVAKNL-AA-

HAYYVD HRNARP AYLEKFYAH INWEFVAKAYEWALK--EGMGSVS HAYYVDHRNARP AY LEKF YAH I NWEFVAKAYEWALK--EGMGSVS
HAYYVDHRNARP AY LEKF YAH I NWEFVAKAYEWALK--EGMGSVS

FYANELHSVK FYANELHPVK SFELPAIPYAKDALAPHISAET IEYHYGRHARQTYVTNLNNLIKGT PEFANLPVEEL ITKLDQLPADKKTVLRNNAGGHANHSLFWKGLKK-

Fig. 2. Comparison of the SOD from $C$. jejuni and $C$. coli with SOD from other organisms. The derived amino acid sequences from $C$. jejuni and C. coli are aligned with human MnSOD and both $\mathrm{Mn}$ - and Fe-type SODs from E. coli. Residues conserved between all five enzymes are shown in bold.

with that from C. jejuni (Fig. 3), whilst the putative amino acid sequence of the gene product showed $97 \%$ identity with that of $C$. jejuni (Fig. 2). In addition, the amino acid residues used to classify the $C$. jejuni enzyme as an FeSOD (Parker \& Blake, 1988) were entirely conserved in the C. coli gene product (data not shown).

\section{Expression and electrophoretic analysis of the cloned C. jejuni sod}

The orientation of the cloned open reading frame which encodes the SOD from $C$. jejuni in the vector would allow its transcription to be directed by the lac $Z$ promoter of pTZ19. However, high levels of sod expression were observed in the absence of IPTG (data not shown) and it is possible that transcription of SOD is dependent on the recognition of a Campylobacter sequence as a promoter by the E. coli host. We cannot, however, exclude the possibility that expression of sod is occurring from the lac promoter following titration of the repressor molecule. When cell lysates from E. coli QC1799 harbouring pJSOD1 or pDEL1 were analysed by SDS-PAGE electrophoresis, a major band at $23.5 \mathrm{kDa}$ was seen in both, but not in lysates from cells which had contained the plasmid, pTZ19R (Fig. 4). This corresponds well to the expected molecular mass of SOD $(24.8 \mathrm{kDa})$ and suggests that the integrity of the open reading frame for SOD was retained in the deletion derivative pDEL1. When the equivalent cell lysates were analysed by non-denaturing PAGE and stained specifically, it was apparent that presence of SOD activity in the $\operatorname{sod} A \operatorname{sodB}$ mutant of E. coli was dependent on the presence of PJSOD1 and 
Table 1. Determinant residues in the $C$. jejuni SOD used to distinguish between the Fe-type and Mn-type enzyme

The amino acid residues used to distinguish between FeSOD and MnSOD are aligned and numbered according to Parker \& Blake (1988). Alp, aliphatic side chain; Bas, basic side chain; Mix, more than one residue type; Aro, aromatic side chain.

\begin{tabular}{|c|c|c|c|c|}
\hline Residue no. & MnSOD & FeSOD & C. jejuni & Match \\
\hline \multicolumn{5}{|c|}{ Primary candidates } \\
\hline 76 & Gly & $\mathrm{Ala}$ & Ala & $\mathrm{Fe}$ \\
\hline 77 & Gly & $G \ln$ & Gln & $\mathrm{Fe}$ \\
\hline 84 & Phe & Tyr & Tyr & $\mathrm{Fe}$ \\
\hline 154 & Gln & Ala & $\mathrm{Ala}$ & $\mathrm{Fe}$ \\
\hline 155 & Asp & Gly & Ala & $?$ \\
\hline \multicolumn{5}{|c|}{ Secondary candidates } \\
\hline 23 & Met & Alp & Phe & $?$ \\
\hline 25 & Alp & Tyr & Tyr & $\mathrm{Fe}$ \\
\hline 45 & Aro & Thr & Thr & $\mathrm{Fe}$ \\
\hline 67 & Alp & Ser & Ser & $\mathrm{Fe}$ \\
\hline 69 & $\operatorname{Mix}$ & Gly & Gly & $\mathrm{Fe}$ \\
\hline 70 & Alp & Gly & Gly & $\mathrm{Fe}$ \\
\hline 72 & Bas & Phe & Phe & $\mathrm{Fe}$ \\
\hline 78 & His & Val & Val & $\mathrm{Fe}$ \\
\hline 79 & Alp & $\operatorname{Trp}$ & Tyr & $?$ \\
\hline 83 & Alp & Phe & Phe & $\mathrm{Fe}$ \\
\hline 87 & Mix & Cys & Cys & $\mathrm{Fe}$ \\
\hline 159 & Mix & Thr & Thr & $\mathrm{Fe}$ \\
\hline 173 & Gly & Thr & Val & $?$ \\
\hline 184 & Mix & Asp & Asp & $\mathrm{Fe}$ \\
\hline 186 & Mix & Arg & Arg & $\mathrm{Fe}$ \\
\hline 199 & Val & Leu & His & $?$ \\
\hline 204 & Mix & Phe & Phe & $\mathrm{Fe}$ \\
\hline
\end{tabular}

pDEL1, containing the cloned C. jejuni SOD (Fig. 5). Four electromorphic forms of the sod gene product, probably corresponding to multimeric forms of the protein (with $R_{F}$ values of $0.57,0.60,0.63$ and 0.67 ) were present in both $C$. jejuni and E. coli extracts. However, two additional bands of SOD activity (with $R_{F}$ values of 0.32 and 0.44 ) were present in the recombinant strains of E. coli which may correspond to higher multimers of the protein. Similar results were obtained when cell lysates from C. coli UA585 and E. coli harbouring the cloned sod from the former were analysed by electrophoresis under nondenaturing conditions (data not shown).

\section{DNA/DNA hybridizations}

To confirm the presence of the sod gene in the genome of C. coli and C. jejuni, and to determine its copy number, a portion of the cloned C. jejuni sod gene (a $0.67 \mathrm{~kb}$ HindIII fragment) was labelled and hybridized to digested chromosomal DNA from Campylobacter (Fig. 6). This probe hybridized to a single HindIII fragment of $0.67 \mathrm{~kb}$ in both species and to $11.5 \mathrm{~kb}$ and $9.3 \mathrm{~kb}$ PstI fragments in $C$. jejuni and $C$. coli, respectively. Since the probe

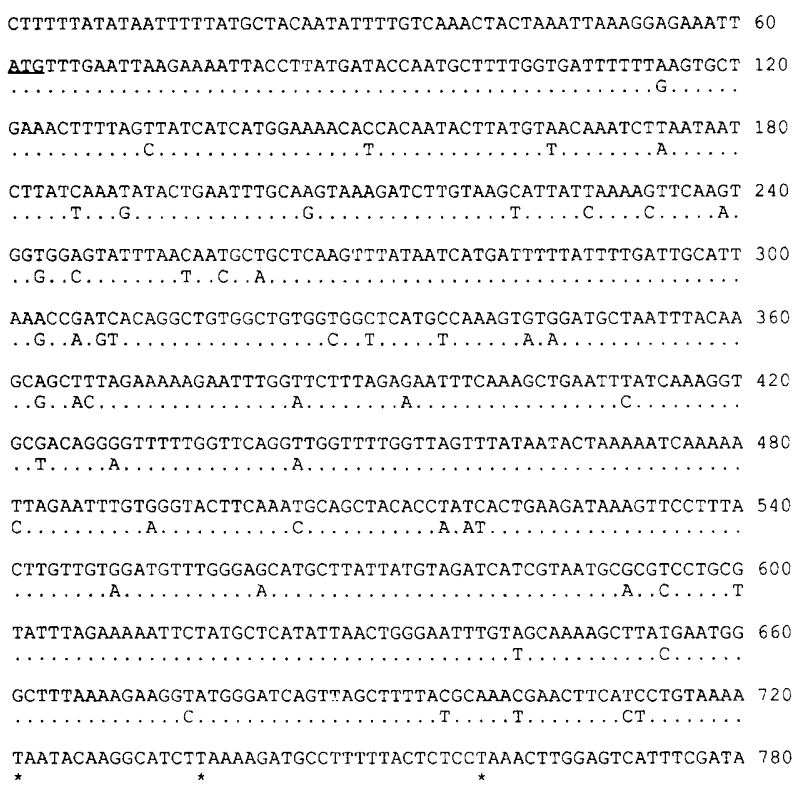

Fig. 3. Complete nucleotide sequence of the sod gene of $C$. coli UA585. The ATG start for the open reading frame is denoted by underlining and the derived amino acid sequence translated from this point is shown in Fig. 2. Stop codons are shown as asterisks. The sequence of the same region of DNA from $C$. jejuni NCTC 11351 is aligned beneath. Only the differences between the $C$. coli and $C$. jejuni sequences are shown.

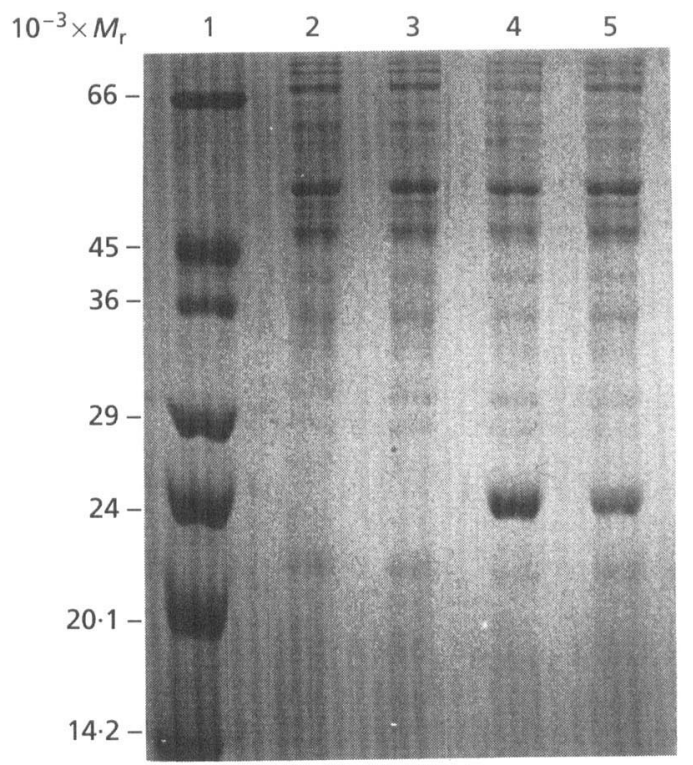

Fig. 4. Expression of the sod gene from C. jejuni in E. coli. Total soluble proteins from recombinant strains of $E$. coli QC1799 were analysed by electrophoresis on a 10\% SDS-PAGE and visualized by Coomassie blue staining. Lanes: 1, molecular mass markers; 2, lysate from E. coli QC1799; 3, lysates from E. coli QC1799 containing plasmids PTZ19; 4, pJSOD1; and 5, PDEL1.

hybridized to a single band in both digests of Campylobacter DNA it is likely that both campylobacter species possess only a single copy of this sod gene. 


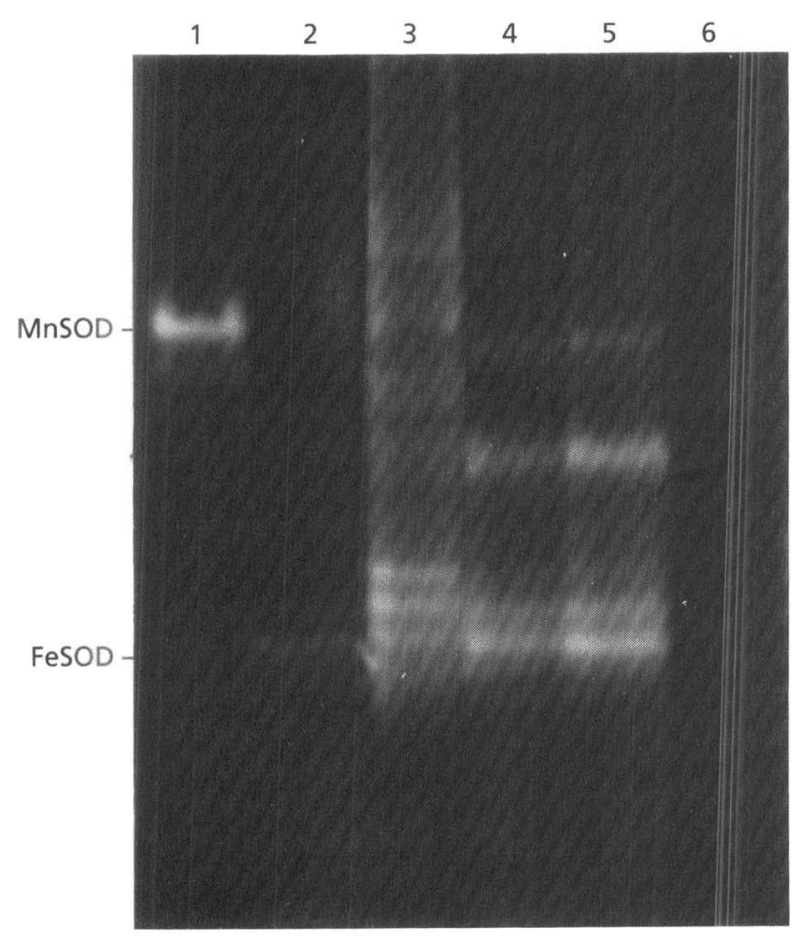

Fig. 5. Detection of SOD activity in C. jejuni and E. coli QC1799 containing recombinant plasmids. Total soluble proteins from $C$. jejuni and recombinant strains of $E$. coli QC1799 were analysed by electrophoresis on a $7.5 \%$ non-denaturing polyacrylamide gel and visualized following specific staining for SOD activity (Beauchamp \& Fridovich, 1971). The positions of $E$. coli MnSOD and FeSOD are shown in lanes 1 and 2. Lane 3 shows a cell lysate from $C$. jejuni. Cell lysates from $E$. coli QC1799 containing the plasmids pJSOD1 (lane 4), PDEL1 (lane 5) and pTZ19R (lane 6) are also shown.

\section{DISCUSSION}

SOD is common to most aerobic organisms and has been implicated in the survival of bacteria under aerobic conditions (Fridovich, 1986; Carlioz \& Touati, 1986). In this study we have cloned the gene for a putative FeSOD from both $C$. jejuni and $C$. coli by complementation of a SOD-deficient mutant of $E$. coli. Despite the often encountered problems in cloning DNA from Campylobacter into E. coli (Taylor, 1992) the genes are expressed efficiently and appear to be maintained stably in E. coli. Characterization of the nucleotide sequence encoding the SOD activity from $C$. jejuni revealed an open reading frame of $660 \mathrm{bp}$ which could encode a putative gene product of 220 amino acids and which showed $71 \%$ and $60 \%$ identity with the E. coli FeSOD and MnSOD, respectively. Sequence analysis of a wide range of MnSODs and FeSODs has identified a number of key residues which are characteristic of the enzymes which utilize different metal ligands. Accordingly, analysis of aligned amino acid sequences may be used to distinguish between Fe- and MnSODs on the basis of a number of primary and secondary single-site substitutions (Parker \& Blake, 1988). The amino acid sequences of the putative

$\begin{array}{llll}1 & 2 & 3 & 4\end{array}$

$\mathrm{kb}$

$11 \cdot 5-$

$9 \cdot 3-$
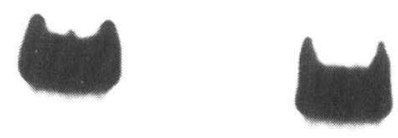

$0.67-$
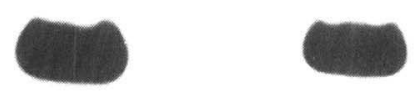

Fig. 6. Hybridization of part of the $C$. jejuni sod gene to chromosomal DNA from $C$. jejuni and $C$. coli. A $0.67 \mathrm{~kb}$ HindIII fragment was labelled and used to probe genomic DNA from $C$. jejuni digested with HindlII (lane 1) and Pstl (lane 3). Genomic DNA from C. coli digested with HindIII (lane 2) and Pstl (lane 4) was also used as a target.

SODs cloned from both $C$. jejuni and $C$. coli indicate that 17 out of 22 determinant residues are the same as for FeSODs. It is likely, therefore, that iron is the metal cofactor for both enzymes. Moreover, since no obvious band of MnSOD activity was observed when cell lysates were examined by non-denaturing electrophoresis it is possible that the iron-type enzyme is the only SOD possessed by these strains of Campylobacter. However, we cannot exclude the possibility that these strains contain an inducible MnSOD which is not expressed under the microaerophilic conditions used to culture the cells. The FeSOD of $C$. jejuni was present in four electromorphic forms when analysed under non-denaturing conditions. Equivalent forms of SOD were also present in lysates of E. coli containing the recombinant SOD. The simplest explanation for these bands of different mobility is that they represent multimeric forms of the protein containing one, two, three and four subunits. This is consistent with observations made with the SOD from other thermophilic bacteria (Fridovich, 1986) and mycobacterial species (Zhang et al., 1991) which form trimers and tetramers.

Given the microaerophilic nature of Campylobacter spp., the survival of these organisms under conditions of 
oxidative stress must be profoundly influenced by the presence of cellular mechanisms which can eliminate reactive oxygen intermediates. As SOD is part of the defence mechanism which protects cells from oxidative stress (Fridovich, 1986) it is likely to play a crucial role in the survival of campylobacters in aerobic environments in which reactive oxygen intermediates are generated. For example, the inclusion of bovine SOD in the growth medium greatly enhances the oxygen tolerance of $C$. jejuni (Hoffman, 1979b) and it has been suggested that the aerotolerance in Campylobacter spp. increases with elevated SOD activity (Kikuchi \& Suzuki, 1984). Having characterized the genes encoding this enzyme we are now in a position to generate isogenic mutants deficient in SOD by gene replacement (Labigne-Roussel et al., 1988) so that the role of SOD in the physiology and virulence of this group of clinically important pathogens can be investigated.

\section{ACKNOWLEDGEMENTS}

We are grateful to D. Touati and D. E. Taylor for the generous gifts of bacterial strains. We thank the Ministry of Agriculture, Fisheries and Foods for financial support for this work.

\section{REFERENCES}

ACMSF (1993). Advisory Committee on the Microbiological Safety of Foods, Interim report on Campylobacter. HMSO.

Beauchamp, C. \& Fridovich, I. (1971). Superoxide dismutase: improved assays and an assay applicable to acrylamide gels. Anal Biocbem 44, 276-287.

Belland, R. J. \& Trust, T. J. (1982). Deoxyribonucleic acid sequence relatedness between thermophilic members of the genus Campylobacter. J Gen Microbiol 128, 2515-2522.

Carlioz, A. \& Touati, D. (1986). Isolation of superoxide dismutase mutants in Escherichia coli: is superoxide necessary for aerobic life? EMBO J 5, 623-630.

Deveureux, J., Haeberli, P. \& Smithies, P. (1984). A comprehensive set of sequence analysis programs for the VAX. Nucleic Acids Res 12, 387--395.

Dower, W. J., Miller, J. F. \& Ragsdale, C. W. (1988). High efficiency transformation of E. coli by high voltage electroporation. Nucleic Acids Res 16, 6127-6145.

Franzon, V. L., Arondel, J. \& Sansonetti, P. J. (1990). Contribution of superoxide dismutase and catalase activities to Shigella flexneri pathogenesis. Infect Immun 58, 529-535.

Fridovich, I. (1978). The biology of oxygen radicals. Science 201, 875-880.

Fridovich, I. (1986). Superoxide dismutases. Adv En₹ymol 58, 61-97.

Gold, L. (1988). Post-transcriptional regulatory mechanisms in Escherichia coli. Annu Rev Biochem 57, 199-233.
Griffiths, P. L. \& Park, R. W. A. (1990). Campylobacters associated with human diarrhoeal disease. J Appl Bacteriol 69, 281-301.

Haas, A. \& Goebel, W. (1992). Microbial strategies to prevent oxygen dependent killing. Free Radical Res Commun 16, 137-157.

Hawley, D. K. \& McClure, W. R. (1983). Compilation and analysis of Escherichia coli DNA promoter sequences. Nucleic Acids Res 11, 2237-2255.

Hoffman, P. S., George, H. A., Kreig, N. R. \& Smibert, R. M. (1979a). Studies of the microaerophilic nature of Campylobacter fetus subsp. jejuni. I. Physiological aspects of enhanced aerotolerance. Can J Microbiol 25, 1-7.

Hoffman, P. S., George, H. A., Kreig, N. R. \& Smibert, R. M. (1979b). Studies of the microaerophilic nature of Campylobacter fetus subsp. jejuni. II. Role of exogenous superoxide anions and hydrogen peroxide. Can J Microbiol 25, 8-16.

Jones, D. M., Sutcliffe, E. M., Rios, R., Fox, A. J. \& Curry, A. (1993). Campylobacter jejuni adapts to aerobic metabolism in the environment. J Med Microbiol 38, 145-150.

Kikuchi, H. E. \& Suzuki, T. (1984). An electrophoretic analysis of superoxide dismutase in Campylobacter spp. J Gen Microbiol 130, 2791-2796.

Labigne-Roussel, A., Courcoux, P. \& Tompkins, L. (1988). Gene disruption and replacement as a feasible approach for mutagenesis of Campylobacter jejuni. J Bacteriol 170, 1704-1708.

Laemmli, U. K. (1970). Cleavage of structural proteins during the assembly of the head of bacteriophage T4. Nature 227, 680-685.

Maniatis, T., Fritsch, E. F. \& Sambrook, J. (1982). Molecular Cloning. A Laboratory Manual. Cold Spring Harbor, NY: Cold Spring Harbor Laboratory.

Mead, D. A., Szcesna-Skorupa, E. \& Kemper, B. (1986). Singlestranded 'blue' $\mathrm{T} 7$ promoter plasmids : a versatile tandem promoter system for cloning and protein engineering. Protein Engineering 1, 67-74.

Parker, M. W. \& Blake, C. C. F. (1988). Iron- and manganesecontaining superoxide dismutases can be distinguished by analysis of their primary structures. FEBS Lett 229, 377-382.

Pitcher, D. G., Saunders, N. A. \& Owen, R. J. (1989). Rapid extraction of bacterial genomic DNA with guanidium thiocyanate. Lett Appl Microbiol 8, 151-156.

Sanger, F., Nicklen, S. \& Coulson, A. R. (1977). DNA sequencing with chain-terminating inhibitors. Proc Natl Acad Sci USA 74, 5463-5467.

Taylor, D. E. (1992). Genetics of Campylobacter and Helicobacter. Annu Rev Microbiol 46, 35-64.

Walker, R. I., Caldwell, M. B., Lee, E. C., Guerry, P., Trust, T. J. \& Ruiz-Palacios, G. M. (1986). Pathophysiology of Campylobacter enteritis. Microbiol Rev 50, 81-94.

Zhang, Y., Lathigra, R., Garbe, T., Catty, D. \& Young, D. (1991). Genetic analysis of superoxide dismutase, the 23 kilodalton antigen of Mycobacterium tuberculosis. Mol Microbiol 5, 381-391.

Received 19 October 1993; revised 30 November 1993; accepted 6 December 1993. 